Иванова Надежда Олеговна

аспирант кафедры экономики и управления в связи Санкт-Петербургского государственного университета телекоммуникаций им. проф. М.А. Бонч-Бруевича

\section{МЕТОДИЧЕСКИЙ ПОДХОД К ОЦЕНКЕ ИНТЕЛЛЕКТУАЛЬНОГО КАПИТАЛА НА ПРЕДПРИЯТИЯХ СЕКТОРА ИНФОРМАЦИОННЫХ ТЕХНОЛОГИЙ}

Аннотация:

В статье предлагается методический подход к разработке комплексного анализа интеллектуального капитала предприятий отрасли инфокоммуникаций, который может быть использован в условиях активного развития экономики знаний. Новизна данного подхода заключается в учете отраслевых специфик развития отдельных составляющих интеллектуального капитала. Предложен алгоритм действий при оценке ИК в секторе информационных технологий. Он в равной степени применим к другим областям исследуемой отрасли.

\section{Ключевые слова:}

интеллектуальный капитал, методы оценки, отрасль инфокоммуникаций, информационные технологии, уровень эффективности, человеческий капитал, интеллектуальная собственность.
Ivanova Nadezhda Olegovna

PhD student, Communication Economics and Managements Department, Saint Petersburg State University of Telecommunications

\section{METHODOLOGICAL APPROACH TO THE ASSESSMENT OF INTELLECTUAL CAPITAL AT THE ENTERPRISES OF INFORMATION TECHNOLOGY SECTOR}

Summary:

The article presents a methodological approach to development of integrated analysis of intellectual capital at enterprises of information technology industry, which can be used in the context of rapid development of the knowledge economy. Scientific relevance of this approach consists in the consideration of the industryspecific features of development of particular components of the intellectual capital. The author suggests an algorithm of actions when assessing the intellectual capital in the information technology sector. It is equally applicable to other areas of the industry.

Keywords:

intellectual capital, assessment methods, information and communications technology industry, information technologies, effectiveness level, human capital, intellectual property.

В современной экономике разработано множество методов оценки рыночной стоимости интеллектуального капитала (далее - ИК) в разрезе предприятия, что свидетельствует о значительной сложности данного вопроса и о том, что традиционные методы анализа активов, в том числе неосязаемых, не способны удовлетворить в необходимой степени возникающие потребности хозяйствующих субъектов [1]. Учитывая специфические особенности составляющих ИК предприятия, на данный момент не представляется возможным разработать единый, универсальный комплексный метод его оценки, который мог бы использоваться в организациях любой отрасли народного хозяйства с одинаковой эффективностью. В связи с этим, опираясь на разработанную ранее классификацию компаний отрасли инфокоммуникаций [2, с. 77], предлагаем вывести алгоритм действий при оценке ИК на этих предприятиях.

Согласно данной классификации, предприятия отрасли инфокоммуникаций подразделяются на три сектора: информационных технологий, услуг связи и строительства объектов связи. Каждый из них в свою очередь состоит из ряда обладающих отличительными характеристиками подвидов организаций. При формировании рекомендаций по оценке ИК, в частности для области информационных технологий, представляется целесообразным использовать следующую последовательность действий:

1) изучение структуры основного капитала;

2) исследование состава занятых на предприятии сотрудников;

3) составление списка развитых и работающих на предприятии элементов ИК на основе п. 1 и 2

4) определение наиболее эффективных методов для оценки выявленных в п. 3 составных частей ИК;

5) выведение комплексной интегральной оценки Ик.

Рынок информационных технологий, сформированный относительно недавно, но активно развивающийся в настоящее время, представлен компаниями сегментов ИТ-услуг, программного обеспечения и оборудования с аппаратно-программными комплексами. На основе изученной бухгалтерской отчетности, статистических данных и информации, находящейся в открытом доступе, от ведущих представителей сегментов ИТ-услуг и программного обеспечения (ЕРАМ Systems, «Компьюлинк», «Ай-теко», «Ланит» и ООО «ИТСК») можно сделать заключение о том, 
что на данных предприятиях из элементов структуры ИК активно работают следующие [3, с. 151]: личностные активы сотрудников (творческий и профессиональный потенциалы); синергетические активы работников (обучение персонала и тренинги); интеллектуальная собственность (патенты на реализуемое ПО); рыночный капитал (рыночная власть, имидж организации). Придерживаясь разработанной последовательности, выделим наиболее эффрективные методы оценки перечисленных элементов ИК [4, с. 348-366; 5] (таблица 1).

Таблица 1 - Уровень эффективности методов оценки отдельных элементов ИК для предприятий сегментов ИТ-услуг и программного обеспечения

\begin{tabular}{|c|c|c|c|}
\hline Элемент Ик & Основной метод & $\begin{array}{c}\text { Второстепенный } \\
\text { метод }\end{array}$ & $\begin{array}{c}\text { Менее эффективный } \\
\text { метод }\end{array}$ \\
\hline $\begin{array}{l}\text { Творческий и } \\
\text { профессиональный } \\
\text { потенциалы }\end{array}$ & $\begin{array}{l}\text { Дисконтированная прибыль } \\
\text { до уплаты налогов } \\
\text { на одного сотрудника }\end{array}$ & $\begin{array}{l}\text { Коэффрициент } \\
\text { профрессиональной } \\
\text { перспективности }\end{array}$ & 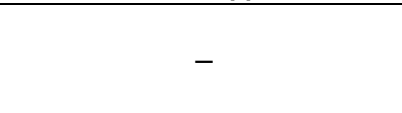 \\
\hline Обучение персонала & $\begin{array}{l}\text { Возврат на инвестиции в } \\
\text { человеческий капитал (ЧК) } \\
\text { (Human capital Return } \\
\text { on Investment) }\end{array}$ & $\begin{array}{l}\text { Метод исторических } \\
\text { затрат }\end{array}$ & $\begin{array}{l}\text { Метод выделения доли } \\
\text { прибыли, приходящейся } \\
\text { на ОИк; метод оценки с } \\
\text { использованием ROI }\end{array}$ \\
\hline Патенты и технологии & $\begin{array}{l}\text { Метод освобождения от ро- } \\
\text { ялти }\end{array}$ & $\begin{array}{l}\text { Метод восстановле- } \\
\text { ния, метод историче- } \\
\text { ских затрат }\end{array}$ & $\begin{array}{l}\text { Метод прямого анализа } \\
\text { сравнения продаж ОИС }\end{array}$ \\
\hline Рыночная власть & Коэффициент Тобина & Доля рынка & Индекс лояльности \\
\hline Бренд & $\begin{array}{l}\text { Метод дисконтированных } \\
\text { денежных потоков }\end{array}$ & 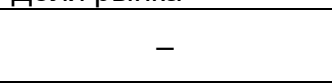 & $\begin{array}{l}\text { Метод суммарных } \\
\text { издержек }\end{array}$ \\
\hline
\end{tabular}

Далее частично рассмотрим основные методы оценки элементов ИК. В связи с тем что профессиональный и творческий потенциалы сотрудников являются составными частями человеческого капитала, стоит отметить, что анализу подлежит только персонал, относящийся к категории доходогенерирующих, что составляет необходимое условие для исследования элементов ЧК. Наиболее предпочтителен для оценки данной составляющей метод дисконтированной прибыли до уплаты налогов на одного сотрудника. Он состоит из двух этапов: определение прибыли на одного сотрудника и перемножение полученного результата на коэффициент дисконтирования:

$$
D E B I T=\frac{E B I T}{N \times(1+r)^{t}},
$$

где $E B I T-$ прибыль до уплаты налогов (берется из бухгалтерской отчетности);

$N$ - среднесписочная численность доходогенерирующих работников предприятия;

$r$ - ставка дисконтирования;

$t$ - период дисконтирования

Формирование человеческого капитала не является окончательным этапом работы с ним, поэтому обучение персонала (развитие ЧК) занимает свое место в составе ИК. Здесь основным выступает метод возврата на инвестиции в человеческий капитал (Human capital Return on Investment) [6]:

T. e.

$$
\text { HCROI }=\text { Revenue }-\frac{\text { Costs-salary and awards }}{\text { salary and awards }},
$$

$$
\text { HCROI = Доход }-\frac{\text { Затраты }- \text { Зарплаты и премии }}{\text { Зарплаты и премии }} \text {. }
$$

Неоднозначность данного способа заключается в том, что, получив некую цифру, сложно определить, высокий это уровень возврата или нет, для чего дополнительно применяют экспертный метод.

При оценке патентов и технологий на предприятиях сегмента ПО приоритетными являются методы доходного подхода, в частности метод освобождения от роялти [7]. Наиболее эффективным способом оценки стоимости брендов принято считать дисконтирование денежных потоков, введенное в обиход посредством деятельности компании Interbrand. Данная методика включает четыре основных этапа: финансовый прогноз, анализ роли бренда, оценку его силы и расчет стоимости.

На заключительном этапе анализа ИК сегментов ИТ-услуг и программного обеспечения предлагается вывести комплексную интегральную оценку: сначала необходимо всем оцениваемым элементам ИК присвоить весовые коэффицценты значимости на предприятии. Например, патенты и технологии $-k=5$, профессиональные и творческие потенциалы персонала $-k=4$, бренд $-k=3$, обучение сотрудников $-k=2$, рыночная власть $-k=1$ (определяется экспертным путем); затем полученные взвешенные значения нужно привести к единому среднему: 
где $\quad I K_{i}-$ оцениваемый элемент ИК;

$$
I K=\sum_{i=1}^{5} \frac{k_{i} I K_{i}}{5}
$$

$k_{i}$ - весовой коэфрфициент ИК

IK - интегральная оценка ИК компании изучаемого сектора.

Третий сегмент рынка информационных технологий представляют российские производители ИТ-оборудования (DEPO Computers, ГК «Аквариус», «Элтекс», «Т-платформы»). В основу создания практических рекомендаций положен годовой отчет компании ОАО «Т-платформы» за 2015 г. [8]. На предприятиях сектора оборудования и программно-аппаратных комплексов из составляющих ИК сформированы и развиваются следующие: личностные активы сотрудников (профессиональный потенциал, образование и специальные знания); интеллектуальная собственность (патенты на изобретение, промышленный образец, полезную модель, товарный знак); рыночный капитал (база клиентов, бренд).

В соответствии с приведенными ранее этапами формирования практических рекомендации по оценке элементов ИК следует определить наиболее эффективные методы анализа перечисленных составляющих ИК (таблица 2).

Таблица 2 - Уровень эффективности методов оценки элементов ИК для предприятий сегмента ИТ-оборудования

\begin{tabular}{|l|l|l|l|}
\hline \multicolumn{1}{|c|}{ Элемент Ик } & \multicolumn{1}{|c|}{ Основной метод } & \multicolumn{1}{|c|}{$\begin{array}{c}\text { Второстепенный } \\
\text { метод }\end{array}$} & $\begin{array}{c}\text { Менее эффективный } \\
\text { метод }\end{array}$ \\
\hline $\begin{array}{l}\text { Профессиональный } \\
\text { потенцил }\end{array}$ & $\begin{array}{l}\text { Дисконтированная } \\
\text { прибыль до уплаты налогов } \\
\text { на одного сотрудника }\end{array}$ & $\begin{array}{l}\text { Коэффициент про- } \\
\text { фессиональной пер- } \\
\text { спективности }\end{array}$ & - \\
\hline $\begin{array}{l}\text { Образование и специаль- } \\
\text { ные знания }\end{array}$ & $\begin{array}{l}\text { Уровень образования/ква- } \\
\text { лификации }\end{array}$ & - & - \\
\hline $\begin{array}{l}\text { Патенты на изобретение, } \\
\text { промышленный образец } \\
\text { и т. д. }\end{array}$ & $\begin{array}{l}\text { Метод освобождения } \\
\text { от роялти }\end{array}$ & $\begin{array}{l}\text { Метод восстановле- } \\
\text { ния, метод историче- } \\
\text { ских затрат }\end{array}$ & $\begin{array}{l}\text { Метод прямого } \\
\text { анализа сравнения } \\
\text { продаж Оис }\end{array}$ \\
\hline $\begin{array}{l}\text { Товарный знак (ТЗ) и знак } \\
\text { обслуживания }\end{array}$ & $\begin{array}{l}\text { Метод дисконтирования } \\
\text { будущихприбылей }\end{array}$ & $\begin{array}{l}\text { Метод сравнитель- } \\
\text { ного анализа продаж }\end{array}$ & $\begin{array}{l}\text { Метод индексации } \\
\text { затрат }\end{array}$ \\
\hline База клиентов & $\begin{array}{l}\text { Метод прямой капитализа- } \\
\text { ции }\end{array}$ & $\begin{array}{l}\text { Метод сравнитель- } \\
\text { ного анализа продаж }\end{array}$ & $\begin{array}{l}\text { Метод суммарных } \\
\text { издержек }\end{array}$ \\
\hline Бренд & $\begin{array}{l}\text { Метод дисконтированных } \\
\text { денежных потоков }\end{array}$ & $\begin{array}{l}\text { Метод суммарных } \\
\text { издержек }\end{array}$ \\
\hline
\end{tabular}

Образование и специальные знания как элементы ИК предлагаем оценить с помощью расчета уровня квалификации/образования i-го сотрудника с последующим выведением интегрального показателя в целом по предприятию:

$$
\mathrm{K}=\frac{(\text { ОБ }+\mathrm{CT}+\mathrm{CP})}{3},
$$

где ОБ - оценка образования: 1 - среднее специальное образование, 2 - высшее;

СТ - оценка стажа работы по специальности;

СР - коэффрициент сложности работы (в компании разрабатывается система присвоения значений коэффрициента видам работ);

3 - величина, соответствующая сумме максимальных оценок по образованию и стажу.

При оценке стоимости прав на ТЗ предпочтение отдается доходному подходу (методу дисконтированных будущих прибылей), что связано с отражением его максимально реальной ценности [9, с. 229-235]. Выгоды от использования анализируемого Т3 определяются посредством прямого сопоставления величины риска и времени получения денежного потока от его применения с аналогичными показателями без учета Т3:

$$
V_{\mathrm{T}_{д}}=\sum_{i=1}^{n} \Delta \mathrm{PM}_{i} \times \Delta V_{i} \times(1+d)^{-(i-0,5)},
$$

где $\quad V_{\text {тзд }}$-стоимость Т3, рассчитанная на основе доходного подхода;

$\Delta \mathrm{PM}_{i}$ - дополнительная маржа прибыли, обусловленная наличием Т3, ожидаемая в і-м году;

$\Delta V_{i}$ - дополнительный объем продаж, связанный с использованием Т3;

$i$ - порядковый номер года получения дохода от Т3;

$d$ - ставка дисконтирования, определенная методом рыночной экстракции. 
Клиентские отношения или база клиентов, будучи одними из наиболее сложных для анализа элементов ИК, выступают самыми важными для поддержания функционирования предприятия. В качестве максимально эфффективного метода оценки данного элемента предлагаем использовать метод прямой капитализации, целью которого является определение NPV ожидаемых доходов, поступающих в компанию на протяжении предполагаемого остаточного «срока службы» клиентских отношений. Стоимостью последних в таком случае будет ожидаемый (средний) годовой доход от клиентов (за вычетом всех расходов), разделенный на ставку прямой капитализации (например, WACC для приобретаемого актива).

В заключение стоит отметить, что новизна предлагаемого подхода к оценке ИК состоит в предложении оценивать его не как единый, неделимый актив, а как комплексный, состоящий из ряда компонентов. Однако оценке подлежат не все его элементы, а только те, которые развиты в достаточной степени и работают на предприятии конкретного типа. Выборку составных частей ИК следует проводить на базе изучения структуры основного и человеческого капиталов. Далее оценка осуществляется с использованием определенных в данной работе приоритетных методов. Таким образом, придерживаясь описанной методики оценки ИК, компании, относящиеся к другим сегментам отрасли инфокоммуникаций (секторам услуг связи и строительства объектов связи), смогут проанализировать интеллектуальный капитал сотрудников, работающих у них, основываясь на своей сегментной специфике.

\section{Ссылки:}

1. Макаров В.В., Гусев В.И., Синица С.А. Методический подход к оценке информационных ресурсов // Информационные технологии и телекоммуникации : электронный научный журнал. 2013. № 3 (3). С. 72-78.

2. Макаров В.В., Иванова Н.О. Классификация инфокоммуникационных предприятий на основе их инновационного потенциала // Проблемы современной экономики. 2016. № 1 (57). С. 76-79.

3. Иванова Н.О. Сравнительный анализ подходов к трактовке понятия «интеллектуальный капитал» // Наука и образование в современной конкурентной среде : материалы МНПК. Уфа, 2014. Ч. ІІІ. С. 148-153.

4. Макаров В.В., Семёнова М.В., Ястребов А.С. Интеллектуальный капитал. Материализация интеллектуальных ресурсов в глобальной экономике : монография / под ред. В.В. Макарова. СПб., 2012. 688 с.

5. Леонтьев Б.Б. Цена интеллекта. Интеллектуальный капитал в российском бизнесе. М., 2002. 196 c.

6. Фитц-енц Я. Рентабельность инвестиций в персонал. Измерение экономической ценности персонала : пер. с англ. M., 2006. 320 c.

7. Парр Р.Л. Оценка патентов. Ставки роялти. Оценка методом освобождения от роялти [Электронный ресурc]. URL: http://www.kwinto.ru/en/node/569 (дата обращения: 30.12.2016).

8. См.: Годовой отчет компании ОАО «T-платформы» за 2015 г. [Электронный ресypc]. URL: http://www.t-platforms.ru/images/stories/finance/god_buh_2015.pdf (дата обращения: 30.12.2016).

9. Карпова Н.Н., Азгальдов Г.Г. Оценка стоимости интеллектуальной собственности и нематериальных активов : учебное пособие. М., 2007. 448 с.

\section{References:} Russian).

Fitz-enz, J 2006, The ROI of human capital: Measuring the economic value of employee performance, Moscow, 320 p., (in

Ivanova, NO 2014, 'Comparative analysis of approaches to the interpretation of the intellectual capital concept', Nauka $i$ obrazovaniye $v$ sovremennoy konkurentnoy srede: materialy MNPK, Ufa, Part III, pp. 148-153, (in Russian).

Karpova, NN \& Azgaldov, GG 2007, Cost valuation of intellectual property and intangible assets, study guide, Moscow, 448 p., (in Russian).

Leontiev, BB 2002, The price of intelligence. Intellectual capital in Russian business, Moscow, 196 p., (in Russian).

Makarov, VV, Gusev, VI \& Sinitsa, SA 2013, 'Methodical approach to the evaluation of information resources', Informatsionnyye tekhnologii i telekommunikatsii: elektronnyy nauchnyy zhurnal, no. 3 (3), pp. 72-78, (in Russian).

Makarov, VV \& Ivanova, NO 2016, 'Classification of infocommunication enterprises based on their innovative capacity', Problemy sovremennoy ekonomiki, no. 1 (57), pp. 76-79, (in Russian).

Makarov, VV, Semyonova, MV, Yastrebov, AS \& Makarov, VV (ed.) 2012, Intellectual capital. Materialization of intellectual resources in the global economy, monograph, St.-Petersburg, 688 p., (in Russian).

Parr, RL 2016, Valuation of patents. Royalty rates. Valuation by the method of royalty exemption, viewed 30 December 2016 , $<$ http://www.kwinto.ru/en/node/569>, (in Russian). 